\title{
Vasopressin increases GAGA binding activity to the V1b receptor promoter through transactivation of the MAP kinase pathway
}

\author{
Simona Volpi, Ying Liu and Greti Aguilera \\ Section on Endocrine Physiology, Developmental Endocrinology Branch, National Institute of Child Health and Human Development, National Institute of Health, Bethesda, \\ Maryland 20892-1303, USA \\ (Requests for offprints should be addressed to G Aguilera; Greti-Aguilera@ nih.gov)
}

\begin{abstract}
Previous studies show that binding of nuclear proteins to GAGA repeats (GAGA box) in the vasopressin type $1 \mathrm{~b}$ receptor $(\mathrm{V} 1 \mathrm{bR})$ promoter is essential for transcriptional initiation of the gene. To determine whether increased vasopressin (VP) during stress activates $\mathrm{V} 1 \mathrm{bR}$ expression through the GAGA box, we examined the effects of VP on GAGA binding activity and on the ability of the V1bR promoter to recruit RNA polymerase in the hypothalamic cell line, H32. In chromatin immunoprecipitation assays, VP induced RNA polymerase II recruitment by the wild type V1bR promoter but not by a construct with the major GAGA box deletion. VP (10 min) also increased binding of nuclear proteins to radiolabeled GAGA oligonucleotides in electromobility shift assays. VP-induced GAGA binding activity was potentiated by the protein kinase $C$ inhibitor, calphostin $C$, and was prevented by the MEK inhibitor, UO126, and the epidermal growth factor receptor (EGFR) inhibitor, AG1478, suggesting that VP activates GAGA binding through transactivation of the EGFR. This was confirmed by western blot experiments showing rapid increases in phospho ERK after incubation with VP, an effect that was potentiated by calphostin C and inhibited by UO12 and AG1478, as well as by the ability of VP to phosphorylate the EGFR. Using receptor selective VP analogs we showed that both V1aR and V1bR subtypes can mediate GAGA binding activation in H32 cells. This study demonstrates that VP stimulates GAGA binding to the V1bR promoter through transactivation of the EGFR and MAP kinase. The data support the hypothesis that VP contributes to pituitary V1bR upregulation during stress through GAGA binding-mediated transcriptional activation.
\end{abstract}

Journal of Molecular Endocrinology (2006) 36, 581-590

\section{Introduction}

The nonapeptide, vasopressin (VP), synthesized in parvocellular neurons of the paraventricular nucleus $(\mathrm{PVN})$ of the hypothalamus is an important regulator of pituitary adrenocorticotropin (ACTH) secretion, mainly by potentiating the stimulatory effect of corticotropin releasing hormone (Gillies et al. 1982, Antoni 1993, Aguilera 1994). The expression and secretion of VP into the pituitary portal circulation (Plotsky 1988, Berkenbosch et al. 1989, Engler et al. 1989, de Goeij et al. 1991, Tannahill et al. 1991, Whitnall 1993) as well as the number of VP receptors in the pituitary, increase markedly during the late phase of an acute stress and following chronic stress (Aguilera et al. 1994, Aguilera \& Rabadan-Diehl 2000). The effect of VP in the pituitary corticotrope cells are mediated by the vasopressin type $1 \mathrm{~b}$ receptor (V1bR) subtype, which is coupled to phospholipase $\mathrm{C}$, leading to increases in cytosolic calcium and activation of protein kinase C (PKG) (Jard et al. 1987, Carvallo \& Aguilera 1989, Antoni 1993). The parallel changes in V1bR content in the pituitary and corticotrope responsiveness observed in a number of experimental conditions have suggested that V1bR regulation contributes to the adaptation of the hypothalamic-pituitary-adrenal (HPA) axis during stress (Aguilera 1994). Therefore, a better understanding of the mechanisms controlling VlbR expression may prove important for the management of stress-related disorders involving HPA axis disregulation.

It has been shown that the increases in VP binding to pituitary membranes observed $4 \mathrm{~h}$ after stress are associated with biphasic changes in VlbR mRNA in which there is an initial decrease by $2 \mathrm{~h}$, followed by a late increase by $4 \mathrm{~h}$. These rapid changes in mRNA expression suggest that rapid activation of $\mathrm{V} 1 \mathrm{bR}$ gene transcription is required in order to restore $\mathrm{V} 1 \mathrm{bR}$ mRNA levels (Rabadan-Diehl et al. 1995).

We have previously shown that interaction of a pituitary nuclear protein complex with GAGA repeats located near the transcription start point of the VlbR promoter (inverted GAGA box) is critical for transcriptional activation of the gene (Volpi et al. 2002). GAGA repeats were first identified in Drosophila heat shock 
protein and histone gene promoters, where they were found to bind a protein called GAGA factor, encoded by the essential Trithorax-like (Trl) gene (Biggin \& Tjian 1988b, Gilmour et al. 1989, Soeller et al. 1993, Farkas et al. 1994). In these genes, GAGA factor binding to GAGA repeats has been implicated in chromatin structure and in remodeling and initiation of transcription (Biggin \& Tjian 1988, Gilmour et al. 1989, Farkas et al. 1994). Transfection of Drosophila GAGA factor markedly increases V1bR promoter activity, and gel shift assays using pituitary nuclear proteins revealed marked increases in GAGA binding activity during stress. Moreover, the increases in GAGA binding activity were rapid, $30 \mathrm{~min}$ after initiation of stress, suggesting that activation of the binding protein is mediated by phosphorylation (Volpi et al. 2002). Since the secretion of VP increases during stress and there is evidence suggesting that VP could be involved in the regulation of its own receptor (Volpi et al. 2004), it is possible that VP induces GAGA binding activation with consequent stimulation of V1bR transcription.

In the present study we tested the hypothesis that VP contributes to the transcriptional regulation of the V1bR by activating the binding of GAGA binding proteins to the V1bR promoter. A problem with these studies has been the lack of availability of a cell line with reasonable endogenous receptor expression. We have previously reported endogenous V1bR expression in the hypothalamic cell line, H32. However, current passages of these cells show very low level of expression of the receptor and we have not been able to obtain consistent results when evaluating changes of endogenous gene expression. For this reason, we sought to examine the effects of VP on RNA polymerase II recruitment by the V1bR promoter as an index of transcriptional activity. In addition, we used gel shift assays to examine the effects of VP on the ability of nuclear proteins to bind to GAGA repeats.

\section{Materials and methods}

\section{Cell culture and treatments}

The hypothalamic cell line, H32, provided by Dr Joachim Spiess, Goettingen, Germany, was cultured in Dulbecco's modified Eagle's medium (DMEM) (Life Technologies, Inc.) containing 10\% fetal bovine serum (FBS) (Life Technologies, Inc.), 10\% horse serum and $1 \%$ penicillin/streptomycin (Life Technologies, Inc.). After $24 \mathrm{~h}$ culture in $100 \mathrm{~mm}$ plates $\left(15 \times 10^{5}\right.$ per plate $)$, at $37{ }^{\circ} \mathrm{C}$ under $5 \% \mathrm{CO}_{2} / 95 \%$ air, the medium was changed to serum-free medium containing $0 \cdot 1 \% \mathrm{BSA}$ before incubation with VP $(10 \mathrm{nM})$, or human epidermal growth factor (hEGF; $200 \mathrm{ng} / \mathrm{ml}$ ) (R\&D Systems Inc., Minneapolis, MN, USA). To determine the signaling pathways and receptor subtype mediating the effects of VP, cells were incubated in the presence and absence of the following: the non-peptide V1bR antagonist, SSR149415, $100 \mathrm{nM}$; the Vla receptor (VlaR) antagonist, SR49059, $100 \mathrm{nM}$ (both provided by Dr G Serradeil-le Gal, Sanofi-Synthlab, Toulouse, France); the epidermal growth factor receptor (EGFR) inhibitor, AG1478, $100 \mathrm{nM}$ (CalBiochem, San Diego, CA, USA); the PKC inhibitor, calphostin $\mathrm{C}, 1 \mu \mathrm{M}$ (Biomol Research Lab., Plymouth Meeting, PA, USA); and the MEK inhibitor, UO126, $10 \mu \mathrm{M}$ (Tocris, Ellisville, MO, USA). The VlbR agonist d[Cha $\left.{ }^{4}\right]-$ arginine vasopressin (d[Cha $\left.{ }^{4}\right] \mathrm{AVP}$ ), provided by $\mathrm{Dr}$ Maurice Manning (Toledo, OH, USA) was used at a concentration of $10 \mathrm{nM}$. After incubation for the time periods indicated in the Results section and the figure legends, cells were processed for electrophoretic mobility shift assay (EMSA) or western blot analysis of phospho ERK1/2.

\section{Electrophoretic mobility shift assay}

Nuclear extracts from H32 cells were prepared using NE-PER nuclear and cytoplasmic extraction reagent (Pierce, Rockford, IL, USA) supplemented with protease and phosphatase inhibitors (Sigma, St Louis, MI, USA) and $2 \mathrm{mM}$ phenylmethylsulfonyl fluoride (Sigma). Double-stranded oligonucleotide probes were synthesized as complementary single strands (Sigma Genosys, The Woodlands, TX, USA), and annealed at $80{ }^{\circ} \mathrm{C}$ for 20 min followed by slow cooling to room temperature overnight. Aliquots of 25 pmol GAGA double-stranded oligonucleotides were end-labeled using T4 polynucleotide kinase (New England BioLabs, Inc, Ipswich, MA, USA) and $50 \mathrm{pmol}\left[\gamma^{-33} \mathrm{P}\right] \mathrm{ATP}$ (Perkin Elmer Life Sciences, Wellesley, MA, USA) for $45 \mathrm{~min}$ at $37^{\circ} \mathrm{C}$, in a total volume of $50 \mu \mathrm{l}$. Labeled GAGA probe was purified by centrifugation through a Sephadex G-25 column (Roche Molecular Biochemicals, Indianapolis, IN, USA). The sequences of the probe used for EMSA was GTGACA $($ GAGA $\times 3)$ GGGAAA, which corresponded to 3GAGA repeats flanked by the 6 nucleotides found upstream and downstream of the GAGA box in the VlbR. The incubation mixture contained $1 \mu \mathrm{g}$ nuclear extract, $25 \mathrm{mM}$ HEPES pH $7.9,0.5 \mathrm{mM}$ EDTA, $12.5 \mathrm{mM} \mathrm{MgCl} 2,10 \%$ glycerol, $1 \mathrm{mM}$ dithioth-

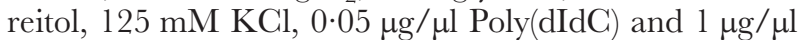
BSA (Sigma) in a total volume of $20 \mu$ l. Radiolabeled oligonucleotide $(1 \mathrm{ng})$ was added to the reaction and incubated for $20 \mathrm{~min}$ at room temperature. Protein concentrations were determined using the sensitive BCA protein assay (Pierce), before and after adjusting the protein concentration. Reaction products were electrophoresed on a 5\% polyacrylamide gel (29:1 acrylamide:bis-acrylamide) in $0.5 \times \mathrm{TBE}$ (Trisborate EDTA buffer) for $90 \mathrm{~min}$ at room temperature at $150 \mathrm{~V}$. Gels were vacuum-heat dried and bands were visualized 
and quantified using a Molecular Dynamics PhoshorImager after two hours exposure at room temperature.

\section{Chromatin immunoprecipitation assay}

H32 cells were transfected with $4 \mu \mathrm{g}$ V1 bRp830-Luc and V1 bRp830 $\triangle$ GAGA-Luc using Lipofectamine Plus (Invitrogen Life Technologies, Carlsbad, CA, USA) in $100 \mathrm{~mm}$ plates. Twenty-four hours after transfection, cells were changed to $0 \cdot 1 \%$ BSA media for $30 \mathrm{~min}$ before incubation with $100 \mathrm{nM} \mathrm{VP}$ for $30 \mathrm{~min}$ or $1 \mathrm{~h}$. Chromatin immunoprecipitation (ChIP) assays were preformed according to the manufacturer's protocol (Upstate Biotechnology, Lake Placid, NY, USA) with some modifications. Briefly, cells were cross-linked by adding formaldehyde directly to culture medium to a final concentration of $1 \%$ and were incubated for $10 \mathrm{~min}$ at room temperature. Cells were then washed twice with ice-cold PBS and collected by scraping in $1 \mathrm{ml}$ ice-cold PBS containing protease (Roche Molecular Biochemicals) and phosphatase (Sigma) inhibitor cocktails. Cells were then resuspended in $250 \mu \mathrm{l} \mathrm{SDS} \mathrm{lysis}$ buffer containing protease and phosphatase inhibitor cocktails and incubated on ice for $10 \mathrm{~min}$. The lysates were sonicated four times for $10 \mathrm{~s}$ (Misonix Incorporated, Farmindale, NY, USA) to reduce DNA fragment length to approximately $500-2000$ base pairs, and subjected to centrifugation for $10 \mathrm{~min}$ to remove debris. Supernatants were collected and diluted 10-fold in ChIP dilution buffer containing protease inhibitor cocktail and phosphatase inhibitor cocktail as above. Aliquots $(50 \mu \mathrm{l})$ of chromatin solution were removed for quantification of the input DNA in the samples before immunoprecipitation. The remaining chromatin solutions were immunocleared with $75 \mu \mathrm{l}$ salmon sperm DNA/protein A agarose slurry for $1 \mathrm{~h}$ at $4{ }^{\circ} \mathrm{C}$ with agitation. Immunoprecipitation was performed using $500 \mu \mathrm{l}$ precleared samples and $10 \mu \mathrm{l}$ RNA polymerase II specific antibody (Pol II (H224) $200 \mu \mathrm{g} / \mathrm{ml}$; Santa Cruz Biotech Inc., Santa Cruz, CA, USA), overnight, under agitation at $4{ }^{\circ} \mathrm{C}$. This was followed by the addition of $60 \mu \mathrm{l}$ salmon sperm DNA/protein A agarose slurry, incubation for $1 \mathrm{~h}$ at $4{ }^{\circ} \mathrm{C}$ under agitation, and sequential washes with low salt immune complex wash buffer, high salt immune complex wash buffer and $\mathrm{LiCl}$ immune complex wash buffer (Upstate Biotechnology) for 3-5 min. After two additional washes in Tris-EDTA (TE) buffer, immunoprecipitated DNA-protein complexes were eluted twice with $1 \%$ SDS and $0 \cdot 1 \mathrm{M}$ $\mathrm{NaHCO}_{3}$. Pooled eluates, as well as the input DNA aliquots from above, were heated at $65^{\circ} \mathrm{C}$ for $4 \mathrm{~h}$ to overnight in $0.2 \mathrm{M} \mathrm{NaCl}$ to reverse the formaldehyde cross-linking. Following incubation at $45^{\circ} \mathrm{C}$ for $1 \mathrm{~h}$ in $40 \mu \mathrm{M}$ Tris-HCl (pH 6.5) containing $10 \mu \mathrm{M}$ EDTA, and $20 \mu \mathrm{g}$ proteinase $\mathrm{K}$, DNA fragments were purified with phenol:chloroform:isoamylalcohol (25:24:1) and ethanol precipitation, reconstituted in distilled water and subjected to PCR using 2 sets of primers designed to amplify the GAGA box region in the V1bR promoter. The first set of primers, yielding a $430 \mathrm{bp}$ band containing the GAGA box, was: forward primer 5'-CCTTTAGGGCATGCTTCTCAG-3'， reverse primer 5 '-TAGGAAACGCAGTCGGAGAA-3'. PGR for detection of the promoter construct with the GAGA box deletion was performed using the forward primer, 5'-CGGGACTAGCTCGTATCATTTG$3^{\prime}$ and the same reverse primer, to yield a $188 \mathrm{bp}$ product. Each cycle consisted of $40 \mathrm{~s}$ at $94^{\circ} \mathrm{C}, 40 \mathrm{~s}$ at $58{ }^{\circ} \mathrm{C}$ and $40 \mathrm{~s}$ at $72{ }^{\circ} \mathrm{C}$, followed by a 10 min extension at $72{ }^{\circ} \mathrm{C}$. The PGR products were separated and visualized in a $2 \%$ Tris acetate/EDTA-agarose gel containing ethidium bromide and sized using PCR markers (Promega). The image was captured electronically and the bands were quantified using KODAK 1D Image Analysis software.

\section{Western blot analysis}

Cells were cultured in 10-cm plates at $80 \%$ confluence, and pre-incubated with vehicle or appropriate signaling inhibitor for $30 \mathrm{~min}$ before addition of VP. After $2.5 \mathrm{~min}$ incubation with VP, cells were lysed with T-PER tissue protein extraction reagent (Pierce), and $20 \mu \mathrm{g}$ protein were loaded and separated in a 10\% SDS-PAGE. For EGFR, 200 to $250 \mu \mathrm{g}$ cell protein lysates in $500 \mu \mathrm{l}$ lysis buffer were immunocleared by incubation for $2 \mathrm{~h}$ at $4{ }^{\circ} \mathrm{C}$ with $50 \mu$ l protein A-agarose beads and centrifuged at $12000 \times \boldsymbol{g}$ for $20 \mathrm{~s}$. Supernatants were transferred to a new tube and incubated overnight at $4{ }^{\circ} \mathrm{C}$ on a rocking platform, after addition of $5 \mu \mathrm{l} \mathrm{EGFR,} \mathrm{1:100} \mathrm{dilution}$ (Cell Signaling Technology, Beverly, MA, USA). Antibody-bound EGFR was immunoprecipitated by addition of $50 \mu \mathrm{l}$ protein $\mathrm{A}$-agarose beads, incubation for $1 \mathrm{~h}$ at $4{ }^{\circ} \mathrm{C}$ and centrifugation. Pellets were washed 5 times with lysis buffer before resuspending in SDS sample buffer, denatured for $5 \mathrm{~min}$ at $95^{\circ} \mathrm{C}$ and loaded into a $4-20 \%$ gradient polyacrylamide gel. All steps before resuspension in SDS buffer were performed in the presence of protease and phosphatase inhibitor cocktail. Proteins were transferred from the gel to a PDVF membrane (Amersham Pharmacia Biotech. Piscataway, NJ, USA), incubated with $5 \%$ blocking agent in $1 \times$ TBST (TBS plus $0 \cdot 1 \%$ Tween-20) for $1 \mathrm{~h}$ and incubated with the anti-phosphorylated ERK or EGFR (Gell Signaling Technology) antibodies at a 1:1000 dilution or phospho-Tyr 1173-EGFR (Santa Cruz, CA, USA) antibody at 1:500 or anti- $\alpha$ tubulin at 1:5000 (Sigma), overnight. After washing in $1 \times$ TBST, membranes were incubated for $1 \mathrm{~h}$ with peroxidaselinked anti-rabbit IgG at a 1:25000 dilution for phospho-ERK, EGFR and phospho-Tyr 1173-EGFR, 
or with anti-mouse IgG at a 1:10 000 dilution for $30 \mathrm{~min}$ for $\alpha$ tubulin used to correct for protein loading. The intensity of the bands was normalized for $\alpha$-tubulin to correct for protein loading. Detection of immunoreactive protein bands was performed using EGL Plus reagents (Amersham Pharmacia Biotech) and exposure to BioMax MR film (Kodak, Rochester, NY, USA). Light transmittance was quantified using a computerized imaging system (Imaging Research, St Catherine, Ontario, Canada), using the public domain NIH Image program (developed at the US National Institutes of Health, and available on the internet at: http:// rsb.Info.nih.gov/nih-image).

\section{Inositol phosphate production}

Transiently transfected $\mathrm{CHO}$ cells were cultured in 24-well plates and labeled with $2.5 \mu \mathrm{Ci} / \mathrm{ml}$ myo$\left[{ }^{3} \mathrm{H}\right]$ inositol per well for $24 \mathrm{~h}$, washed with media containing $0 \cdot 1 \%$ BSA and $10 \mathrm{mM} \mathrm{LiCl}$, and then incubated for 15 min under the conditions indicated in the Results section and in the figure legends. Incubations were stopped by addition of one volume of cold stop solution (1 M KOH, $18 \mathrm{mM}$ sodium tetraborate, $3.8 \mathrm{mM}$ EDTA, $7.6 \mathrm{mM} \mathrm{NaOH}$ ) followed by neutralization with $7 \cdot 5 \% \mathrm{HCl}$. Total inositol phosphates were separated by anion exchange chromatography as previously described (Aguilera et al. 1994) and measured in a liquid scintillation counter.

\section{Measurement of VP receptors}

VP receptors were measured by binding of $\left[\mathrm{H}^{3}\right] \mathrm{VP}$ to $30000 \times \boldsymbol{g}$ membrane fractions prepared from H32 cells pooled from 3 cultures in $10 \mathrm{~cm}$ diameter culture plates at $80 \%$ confluence. Binding inhibition curves were performed using $50 \mu \mathrm{g}$ cell membrane protein, 100000 c.p.m. $\left[\mathrm{H}^{3}\right] \mathrm{VP}$ (Perkin-Elmer Life Science) and increasing concentrations of unlabeled VP or the selective V1bR antagonist SSR149415, or the VlaR antagonist SR49059 $(0 \cdot 1$ to $1000 \mathrm{nM})$, as previously described (Aguilera et al. 1994).

\section{Data analysis}

Statistical significance of the differences between groups was calculated by one-way analysis of variance (ANOVA), followed by the Student-Newman-Keuls method for pairwise multiple comparisons. Statistical significance was set at $P<0 \cdot 05$. Data are presented as means \pm standard error of the mean (s.E.M.) from the values in the number of observations indicated in the Results section or figure legends.

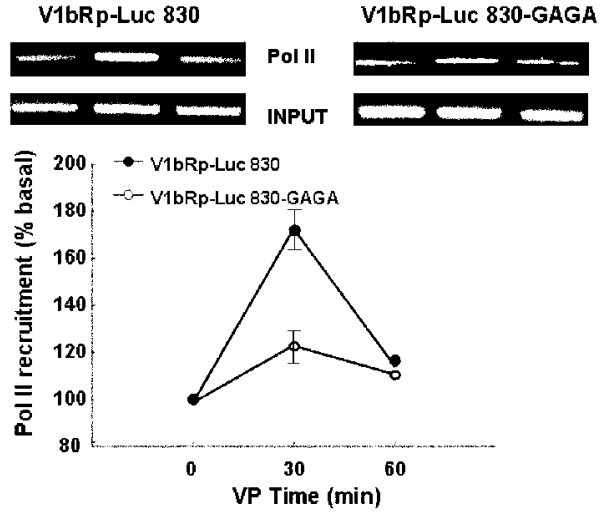

Figure 1 Representative gel (upper panel) corresponding to a chromatin immunoprecipitation assay showing recruitment of RNA polymerase II (Pol II) following incubation of H32 cells with VP. Cells were incubated with VP for 30 or 60 min, $24 \mathrm{~h}$ after transfection with $\mathrm{V} 1 \mathrm{bR}$ promoter luciferase constructs with (V1 bRp-Luc 830) or with deletion of the GAGA box (V1 bRpLuc 830-GAGA). Cross-linked DNA was immunoprecipitated with Pol II antibody and subjected to PCR using primers against the $\mathrm{V} 1 \mathrm{bR}$ promoter. The semiquantitative analysis of the PCR bands after subtraction of the blank values and correction for DNA input in three experiments is shown in the lower panel.

\section{Results}

\section{Effect of VP on Pol II recruitment by the V1bR promoter}

The ability of the V1bR promoter (wild type or with deletion of the main GAGA box) to recruit RNA polymerase II in ChIP assays was used as an index of VlbR transcription in $\mathrm{H} 32$ cells exposed to VP or vehicle. DNA immunoprecipitation with anti Pol II antibody from H32 cells transfected with the wild type VlbR promoter incubated with VP for 30 min yielded VlbR promoter PCR bands with an intensity $80 \%$ higher than that in vehicle-incubated cells. On the other hand, only a minor increase of $20 \%$ was observed in cells transfected with the GAGAless promoter, V1 bRp $830 \triangle$ GAGA. With both constructs, the intensity of the VlbR promoter band had returned to basal levels after $1 \mathrm{~h}$ exposure to VP (Fig. 1). No PCR product was obtained when cross-linked chromatin was immunoprecipitated with a non-related antibody against the carboxyl terminus of the V1bR or using primers against the VlbR 3' untranslated region (not shown).

\section{Effect of VP on GAGA binding activity}

Since previous studies showed transient increases in GAGA binding activity in pituitary nuclear proteins from stressed rats, we sought to examine the ability of 


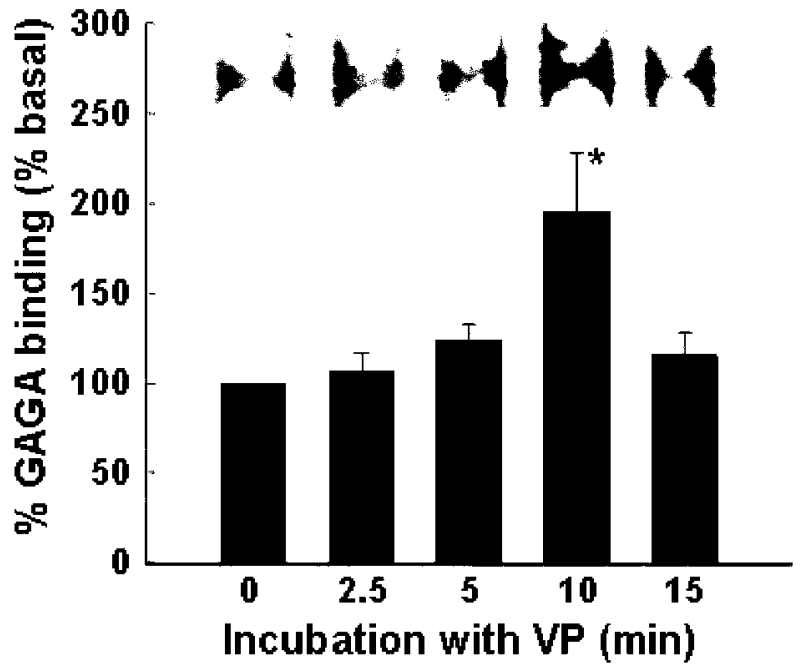

Figure 2 EMSA showing the time course of the binding of nuclear proteins of $\mathrm{H} 32$ cells incubated with VP to GAGA oligonucleotides is depicted above the bars. Quantification of the intensity of the shifted bands was performed using a Molecular Dynamics Phoshorlmager. Bars represent the mean and S.E. of the values obtained in three experiments expressed as percent of basal values. ${ }^{\star} P<0.05$ compared with 0 VP (basal).

VP to mediate the effect of stress, using EMSA with nuclear extracts from $\mathrm{H} 32$ cells following incubation with VP. The time course of the changes in GAGA binding activity is shown in Fig. 2. Binding to radiolabeled GAGA oligonucleotides increased by $94 \cdot 7 \%$ at $10 \min (P<0 \cdot 05, n=3)$ and declined to levels not significantly different from basal by $15 \mathrm{~min}$.

To determine the receptor subtypes present in H32 cells, we examined the effect of subtype specific VP antagonists and a specific V1bR agonist on the ability of VP to induce inositol phosphate formation and to inhibit the binding of $\left[{ }^{3} \mathrm{H}\right] \mathrm{VP}$ to $30000 \times \boldsymbol{g}$ membrane-rich fractions from $\mathrm{H} 32$ cells. In three experiments, incubation of the cells with VP increased total inositol phosphate formation by $2 \cdot 8$-fold $(P<0 \cdot 01)$ but only a minor, though significant increase was observed with the V1bR agonist d $\left[\mathrm{Cha}^{4}\right]$ AVP $(P<0 \cdot 05)$. While stimulation by d[Cha $\left.{ }^{4}\right]$ AVP was completely prevented by the V1bR antagonist, SSR 149415, and was unaffected by the VlaR antagonist, SR49059, the effect of VP was markedly inhibited $(82.4 \%, P<0.01)$ by the VlaR antagonist and only slightly inhibited by the V1bR antagonist $(25.3 \%, P<0 \cdot 05)$, suggesting that the predominant receptor subtype is the V1bR (Fig. 3A). Supporting this data, in binding studies the VlaR antagonist, SR 49059, inhibited $86.5 \%$ of the total binding of $\left[{ }^{3} \mathrm{H}\right]$ VP to $30000 \times \boldsymbol{g}$ membrane fractions of $\mathrm{H} 32$ cells, while the V1bR antagonist inhibited only $31 \%$ of the binding (Fig. 3B). The binding inhibition
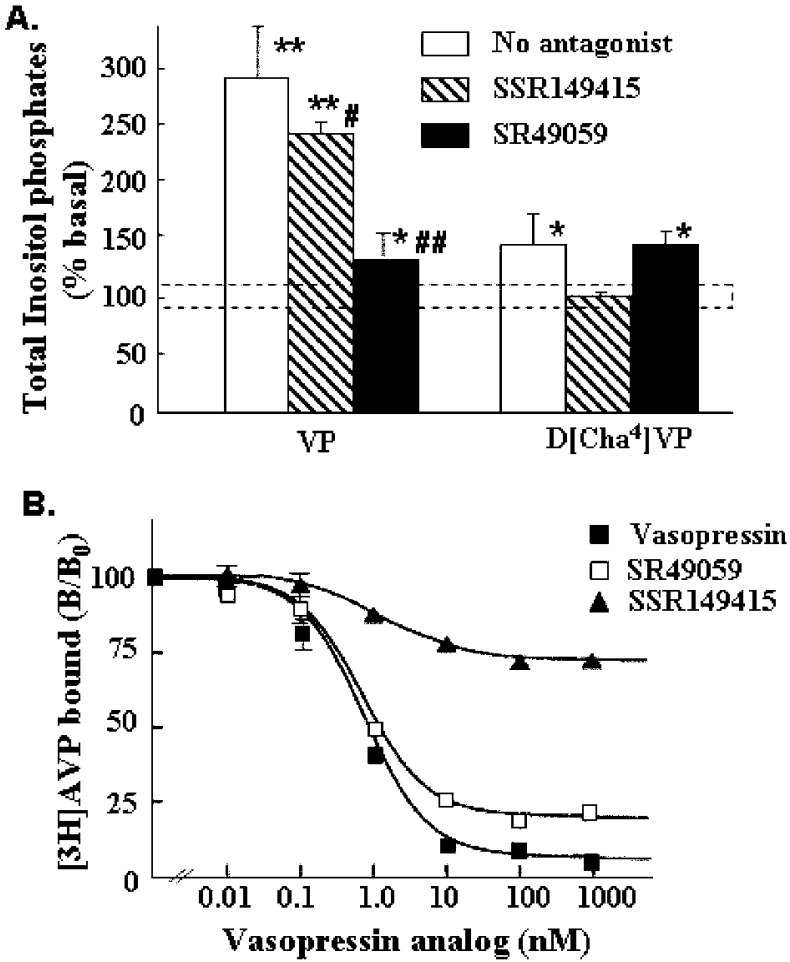

Figure 3 VP receptor subtypes in $\mathrm{H} 32$ cells. (A) Inositol phosphate formation following 20 min incubation of $\mathrm{H} 32$ with VP (no antagonist) or the selective V1bR agonist, d[Cha $\left.{ }^{4}\right] A V P$, in the presence or absence of the selective V1a or V1b receptor antagonists, SR49059 or SSR149415 respectively. Bars are the mean and S.E. of data obtained in three experiments. Basal values and S.E. are indicated by the dotted horizontal bar. ${ }^{* *} P<0.01$ vs basal; ${ }^{*} P<0.05$ vs basal; $\# P<0.05$ vs VP; \#\#, $P<0.01$ vs VP. (B) Inhibition curves of the binding of $\left[{ }^{3} \mathrm{H}\right] \mathrm{VP}$ by VP, the selective V1aR antagonist SR49059, or the V1bR antagonist, SSR149415. Data points represent the mean and S.E. of the data in three experiments. $\mathrm{B} / \mathrm{B}_{0}$, binding in the presence of the competitor over binding in the absence of competitor (maximal binding) ratio.

constants for the V1a and V1b receptor antagonists were similar to that of $\mathrm{VP}$, with $K_{\mathrm{i}}$ values of $0.94 \pm 0.3$, $1 \cdot 1 \pm 0 \cdot 2$ and $0 \cdot 89 \pm 0 \cdot 2 \mathrm{nM}$ respectively.

Since the above data show that H32 cells express both $\mathrm{Vla}$ and V1b receptors, we used receptor subtype specific analogs to determine the type of receptor mediating the activating effect of VP on GAGA binding. As shown in Fig. 4, the VlbR agonist d[Cha $\left.{ }^{4}\right]$ AVP or VP increased GAGA binding activity to similar levels $(177 \cdot 4 \pm 19 \cdot 4 \%$ and $191 \cdot 5 \pm 23 \cdot 4 \%$ respectively). Coincubation of the cells with the VlbR antagonist, SSR 149415, completely prevented the stimulatory effect of the V1bR agonist d[Cha $\left.{ }^{4}\right]$ AVP but reduced the effect of VP by only $26 \%$. The effect of VP was reduced by $33 \%$ by the VlaR antagonist. 


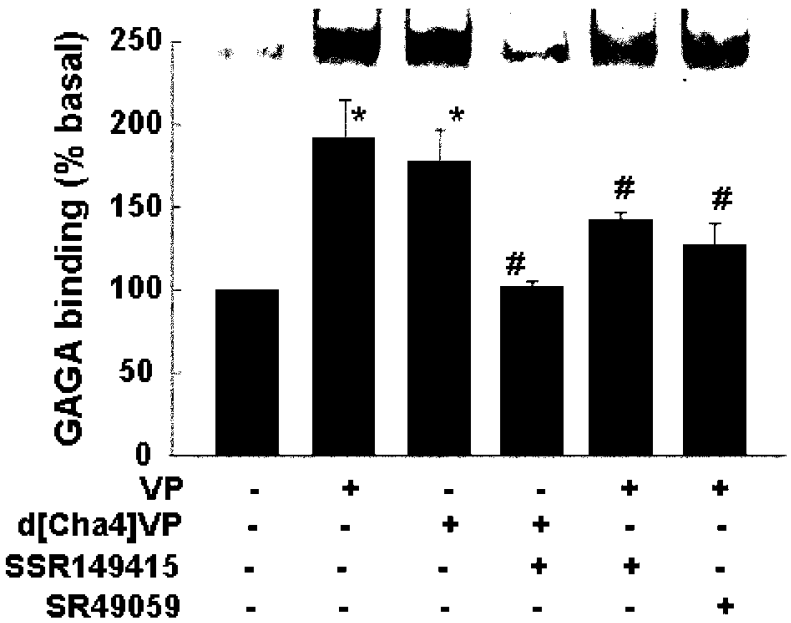

Figure 4 V1 receptor subtype specificity of the effect of VP on GAGA binding activity in H32 cells. EMSA showing the binding of nuclear proteins from $\mathrm{H} 32$ cells incubated with VP (10 min) or the $\mathrm{V} 1 \mathrm{bR}$ agonist $\mathrm{d}\left[\mathrm{Cha}^{4}\right] \mathrm{AVP}$ for $10 \mathrm{~min}$, with or without 30 min pretreatment with the $\mathrm{V} 1 \mathrm{a}$ or $\mathrm{V} 1 \mathrm{~b}$ receptor antagonists, SR49059 and SSR149415 respectively, to GAGA oligonucleotides is depicted above the bars. Quantification of the intensity of the shifted bands was performed using a Molecular Dynamics Phoshorlmager. The graph shows the mean and S.E. of the values in 3 experiments. ${ }^{*} P<0.05$ compared with basal (vehicle treated); \# $P<0.05$ compared with VP-stimulated value.

\section{VP activates GAGA binding through transactivation of the EGFR}

To identify the signaling pathways involved in the activation of GAGA binding by VP, cells were incubated with VP in the presence of several signal transduction inhibitors before testing the activity of nuclear extracts by EMSA. Inhibition of $\mathrm{PKC}$ (the main signaling pathway of $\mathrm{V} 1$ receptors) using the generic $\mathrm{PKC}$ inhibitor, calphostin $\mathrm{C}$, did not prevent but potentiated the stimulatory effect of VP on GAGA binding activity. As shown in Fig. 5, calphostin $\mathrm{C}$ alone had no effect but enhanced the stimulatory effect of VP from $148 \pm 2 \cdot 7 \%$ to $191 \cdot 5 \pm 27 \cdot 5$ of the basal value $(P<0 \cdot 05, n=3)$. On the other hand, activation of GAGA binding by VP was completely abolished in the presence of the MAP kinase (MEK 1 and 2) inhibitor, UO126, or the EGFR inhibitor, AG1478, with values not significantly different from basal levels $(P<0.01$ compared with VP-stimulated activity, $n=3$ ) (Fig. 5). Direct stimulation of the EGFR by incubation of $\mathrm{H} 32$ cells with EGF ( $200 \mathrm{ng} / \mathrm{ml}$ ) caused sustained GAGA binding activation with significant increases at $2 \cdot 5,10$ or $15 \mathrm{~min}(P<0 \cdot 02)$ compared with basal values at all time points $(n=3)$ (Fig. 6). These results suggest that VP can stimulate GAGA binding activity and transcriptional activation of the V1bR by MEK-activation of MAP kinase through transactivation of the EGFR. The ability of VP to transactivate the

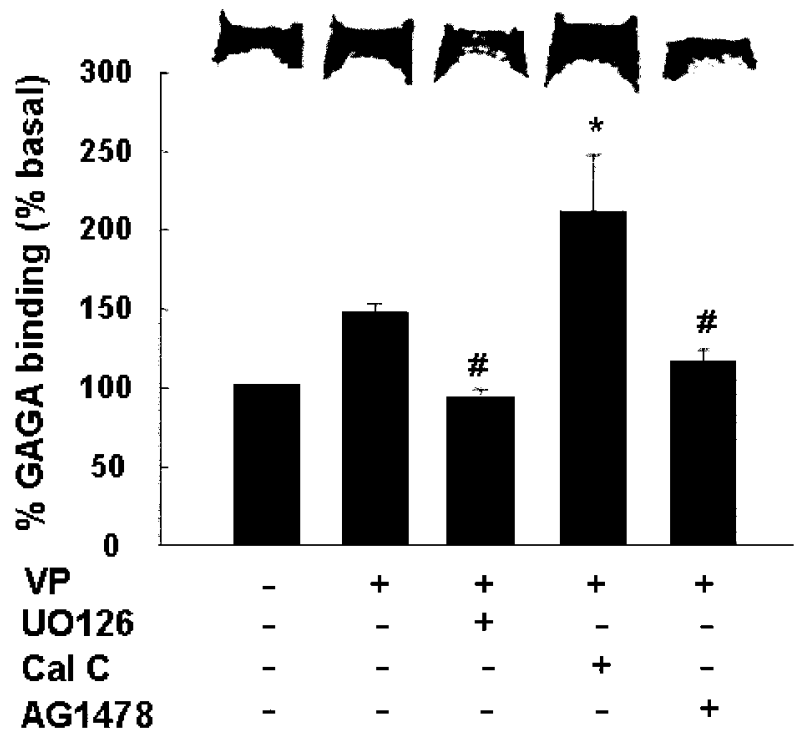

Figure 5 Effect of signaling transduction inhibitors on VP-stimulated GAGA binding activity. EMSA using nuclear proteins from $\mathrm{H} 32$ cells incubated for 30 min with or without U0126 (MEK1/2 inhibitor), calphostin C (Cal C; PKC inhibitor) or AG1478 (EGFR inhibitor) prior to 10 min exposure to VP, and GAGA oligonucleotides is depicted above the bars. Quantification of the intensity of the shifted bands was performed in a Molecular Dynamics Phoshorlmager. The graph shows the mean and S.E. of the values obtained in three experiments. ${ }^{*} P<0.05$ higher than basal (vehicle treated); $\# P<0.05$ lower than VP.

MAP kinase pathway was demonstrated by Western blot analysis for phospho-ERK $1 / 2$ in protein extracts of cells incubated with VP. As shown in Fig. 7A, phospho-ERK levels were undetectable in $\mathrm{H} 32$ cells in basal conditions but became apparent following incubation with VP for $10 \mathrm{~min}$. Similar to GAGA binding activity, VP-induced ERK $1 / 2$ phosphorylation was significantly enhanced by the generic PKC inhibitor, calphostin $\mathrm{C}(P<0.05$ vs VP, $n=3)$ and was markedly inhibited by the MEK $1 / 2$ inhibitor UO126, $(P<0 \cdot 01, n=3)$ and the EGFR inhibitor, AG1478 $(P<0 \cdot 01, n=3)$ (Fig. 7A). To confirm that VP induces ERK1/2 phosphorylation through the EGFR, we examined the effects of VP on EGFR phosphorylation. Western blot analysis of H32 cell proteins using the EGFR antibody after immunoprecipitation with the EGFR antibody revealed a major band of approximately $178 \mathrm{kDa}$, with molecular size consistent with that of the EGFR (Fig. 7B). A weak band at the same position was obtained using an antibody against the phospho-Tyr1173 of the EGFR. As shown in Fig. 7B and $\mathrm{C}$, incubation of the cells with VP for 5 min had no significant effect on total EGFR content but increased markedly $(4 \cdot 3$-fold $)$ the phosphorylated receptor $(P<0 \cdot 01, n=3)$. Preincubation of the cells for $5 \mathrm{~min}$ with the V1 receptor peptide antagonist, Des-Gly[Phaa ${ }^{1}$, 


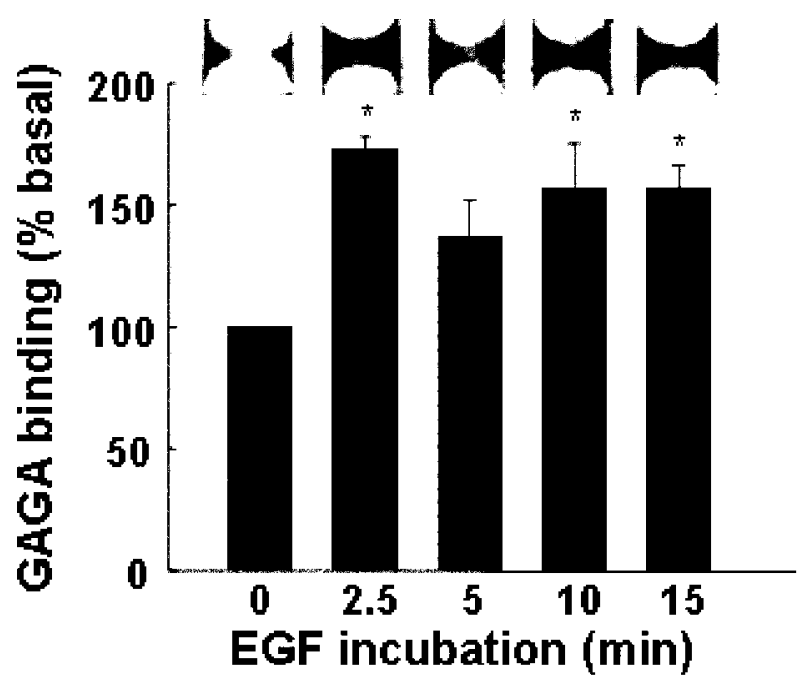

Figure 6 Effect of EGF on GAGA binding activity in H32 cells. Time course of the binding of nuclear proteins to GAGA oligonucleotides after incubation of $\mathrm{H} 32$ cells with EGF. The bars represent the mean and S.E. of the intensity of the shifted bands in the EMSA using a Molecular Dynamics Phoshorlmager, in three different experiments. An image of a representative EMSA is shown above the bars. ${ }^{*} P<0.05$ compared with time 0 (control, no treatment).

D-Tyr $\left.(\mathrm{Et})^{2}, \mathrm{Lys}^{6}{ }^{6}, \mathrm{Arg}^{6}\right] \mathrm{VP}, \quad$ completely prevented the effect of VP on EGFR phosphorylation.

\section{Discussion}

The present study demonstrates that VP increases the binding activity of nuclear proteins to GAGA repeats in the VlbR promoter through activation of the MEK MAP kinase pathway. The data also provide evidence that activation of GAGA binding to the V1bR promoter by VP could mediate transcriptional activation of the VlbR gene. Previous studies showing an association between high VP expression in parvocellular neurons of the PVN and pituitary V1bR upregulation during stress, have suggested that VP can upregulate its own receptor (Volpi et al. 2004). This increase in pituitary VlbRs during stress involves increases in VlbR mRNA and, at least in part, activation of the V1bR gene transcription. For example, acute stress causes biphasic changes in VlbR mRNA levels, with an initial decrease by $2 \mathrm{~h}$ followed by recovery or elevation above the basal values by $4 \mathrm{~h}$ (Rabadan-Diehl et al. 1995). This rapid restoration of VlbR mRNA levels must involve transcriptional activation of the VlbR gene. The present experiments demonstrate that VP can induce recruitment of RNA polymerase II by the VlbR promoter. Since RNA polymerase recruitment is closely associated with initiation of transcription (Kornberg 1999), these

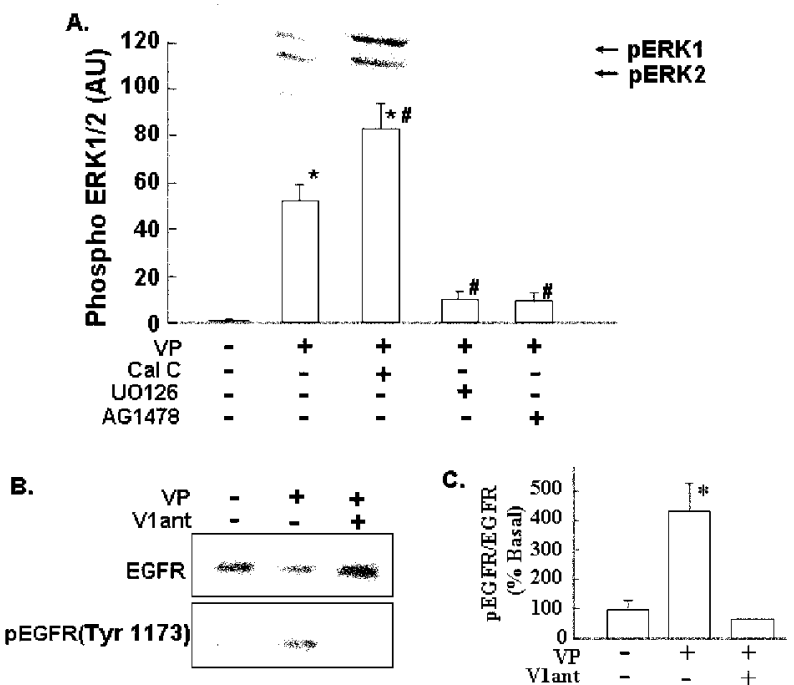

Figure 7 Effect of VP and signaling transduction inhibitors on ERK1/2 phosphorylation in $\mathrm{H} 32$ cells. (A) Cells were pre-incubated with the PKC inhibitor, calphostin $C(\mathrm{Cal} C)$, the MEK1/2 inhibitor, U0126, or the EGFR inhibitor, AG1478, for $30 \mathrm{~min}$ prior to VP treatment for $10 \mathrm{~min}$ and extraction of cell proteins for Western blot for phosphorylated ERK. Bars represent the mean and S.E. of three separate experiments. ${ }^{*} P<0.01$ compared with basal; $\# P<0.05$ compared with VP alone. (B) Images of the EGFR Western blot in a representative experiment. (C) Effect of VP on Tyr 1173-EGFR phosphorylation. H32 cells were incubated with or without VP for 10 min before lysis, EGFR immunoprecipitation and Western blot analysis of EGFR and phospho Tyr 1173-EGFR. When appropriate, $1 \mu \mathrm{M}$ of the non-selective $\mathrm{V} 1$ receptor peptide antagonist, Des-Gly[Phaa ${ }^{1}, \mathrm{D}-\mathrm{Tyr}\left(\mathrm{Et}^{2}{ }^{2}, \mathrm{Lys}^{6}{ }^{6}, \mathrm{Arg}^{8}\right] \mathrm{VP}(\mathrm{V} 1$ ant), was added 5 min prior to incubation with VP. Bars represent the mean and S.E. of data obtained in three experiments, expressed as percent of basal and corrected for total EGFR.

data provide strong support for the hypothesis that VP induces VlbR expression through transcriptional activation. Since stress causes rapid release of VP from the median eminence into the pituitary portal circulation (de Goeij et al. 1991), it is likely that the peptide partially mediates the pituitary VlbR upregulation observed during prolonged stress.

Using reporter genes, we previously demonstrated that binding of a nuclear protein complex to GAGA repeats (GAGA box) in the rat V1bR promoter is essential for transcriptional activation of the V1bR gene (Volpi et al. 2002). The present study supports this concept and provides evidence that activation of VlbR transcription by VP is mediated by the GAGA box. This was first demonstrated by the marked reduction in VP-induced RNA polymerase II recruitment by the V1bR promoter construct lacking the GAGA repeats. Secondly, the ability of VP to enhance GAGA binding activity of nuclear extracts of $\mathrm{H} 32$ cells suggests that VP stimulates VlbR transcription through activation of 
protein binding to the GAGA repeats of the V1bR promoter. While the neuronal cell line, H32, expresses both VlaR and VlbR mRNA, the poor inhibitory effect of the selective VlbR antagonist (compared with the VlaR antagonist) on $\left[{ }^{3} \mathrm{H}\right] \mathrm{VP}$ binding and VPstimulated inositol phosphate formation indicate that the $\mathrm{VlaR}$ is the predominant functional receptor in these cells. The present experiments using receptor subtype specific analogs clearly demonstrate that both Vla and $\mathrm{V} 1 \mathrm{~b}$ receptors can mediate the stimulatory effect of $\mathrm{VP}$ on GAGA binding activity. In spite of the low levels of active V1bR, the V1bR agonist, $d\left[\mathrm{Cha}^{4}\right] \mathrm{AVP}$, used at a concentration known to have no interaction with VlaR (Derick et al. 2002), had an effect similar to that of VP, presumably by interacting with the V1bR. This suggests that occupancy of a small number of receptors is sufficient to elicit full activation of GAGA binding. It is also possible that physical interaction between VlbR and VlaR amplifies the V1bR signal. In this regard it has been shown that a number of $\mathrm{G}$ protein-coupled receptors, including $\mathrm{V} 1$ receptors, can form homodimers and heterodimers (Terrillon 2003, Robert 2005, Young \& Aguilera 2005).

The ability of pituitary nuclear proteins to bind GAGA repeats increases during stress and precedes the increases in VlbR mRNA (Volpi et al. 2002). This rapid and transient increase in pituitary GAGA binding activity is consistent with the hypothesis that the binding of a nuclear protein complex to DNA is activated by phosphorylation. Since this protein complex has been only partially characterized (Volpi et al. 2002), we used gel shift assays with GAGA oligonucleotides and signaling transduction inhibitors to identify signaling pathways mediating activation of GAGA binding proteins by VP. Since PKC is the major mediator of the action of VP in pituitary corticotropes and brain (Bilezikjian et al. 1987, Carvallo \& Aguilera 1989), the fact that the PKC inhibitor, calphostin $\mathrm{C}$, did not inhibit but actually enhanced VP-stimulated GAGA binding activity in the neuronal cell line, H32, was unexpected. The stimulatory effect of the PKC inhibitor suggests that PKC inhibits GAGA binding activity and that an alternative pathway is responsible for the activating effect of VP on GAGA binding protein. A number of $G$ protein-coupled receptors, including V1 receptors, have been shown to initiate EGF or other growth factor receptor signaling in addition to the $G$ proteindependent pathways (Leserer et al. 2000, Ghosh et al. 2001, Chiu 2002, Ferguson 2003, Luttrell 2003, Werry et al. 2005). Such a transactivation of growth factor receptors leads to activation of the MAP kinase pathway and in many instances phosphorylation of nuclear proteins (Luttrell 2003). The present demonstration that the MEK inhibitor, UO126, prevented VP-induced activation of GAGA binding indicates that VP stimulates the binding of nuclear proteins to the $\mathrm{V} 1 \mathrm{bR}$ promoter

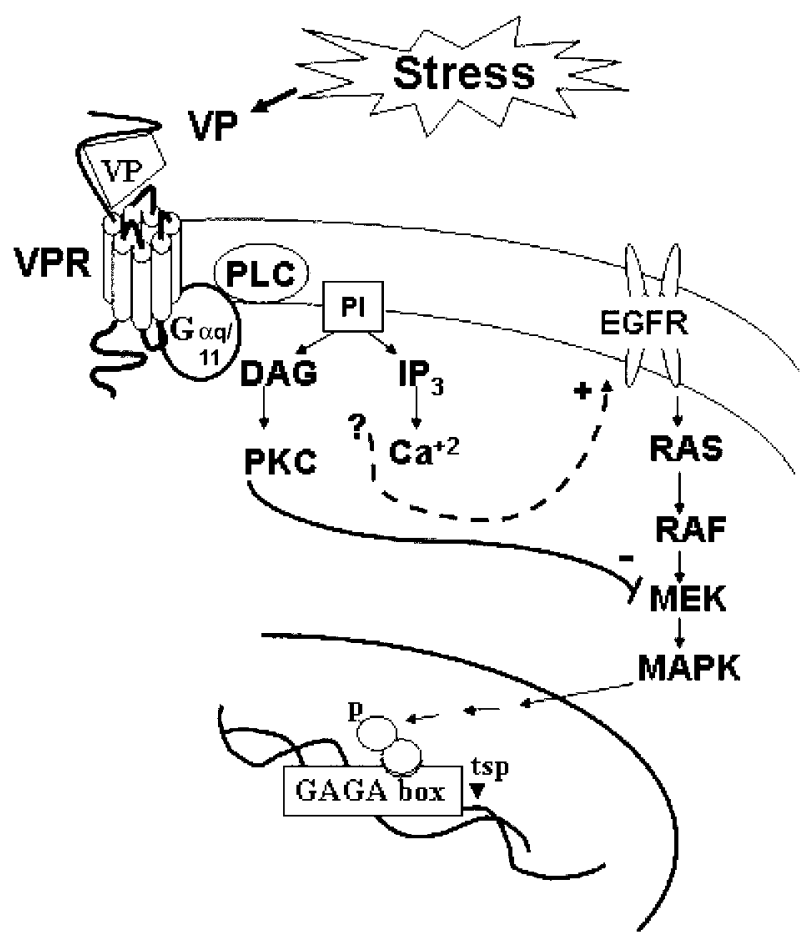

Figure 8 Diagram of the proposed mechanism of transcriptional activation of the V1bR by VP. Activation of V1bR signaling by VP released into the pituitary portal circulation during stress involves transactivation of the EGFR and MAP kinase pathway, leading to phosphorylation and activation of the binding of a nuclear protein capable of interacting with GAGA repeats in the V1bR promoter and activating transcription VPR, vasopressin receptor; PLC, phospholipase C; Gaq/11, alpha subunit of guanyl nucleotide binding protein $\mathrm{q} / 11$; $\mathrm{PI}$, phosphoinositides; DAG, diacyl glycerol; PKC, protein kinase C; IP3, Inositol triphosphate; EGFR, epidermal growth factor receptor; RAS, monomeric guanyl nucleotide binding protein interacting with RAF; RAF, MAP kinase kinase kinase Raf; MEK, MAP/ERK (extracellular signal regulated kinase) kinase; MAPK, mitogen activated protein kinase.

through MAP kinase-dependent phosphorylation. In addition, the experiments confirm that VP does indeed induce ERK1/2 phosphorylation in the H32 cell line. The fact that the effects of VP, both on ERK phosphorylation and GAGA binding activation, were blocked by the EGFR inhibitor and were mimicked by EGF suggests that MAP kinase activation by VP requires the involvement of the EGFR. The present demonstration that VP causes rapid phosphorylation of the EGFR, an effect that is prevented by a non-selective V1 VP receptor, confirms the fact that VP causes transactivation of the EGFR and supports an essential role of the EGFR on activation of the MAP kinase pathway by VP.

A GAGA binding protein has been implicated in the transcriptional regulation of vertebrate genes, such as the human type 1 angiotensin II receptor (AT1R), the rat serine protease inhibitor 1 , and the Xenopus 
stromelysin-3 gene (Li et al. 1998, Simar-Blanchet et al. 1998, Wyse et al. 2000). For the AT1 receptor and serine protease inhibitor genes, it has been shown that GAGA binding to the promoter is required for transcriptional initiation (Leverrier 2000). This is consistent with previous studies using reporter genes showing that the GAGA box is required for basal V1bR promoter activity (Volpi et al. 2002), and the present data showing rapid increases in GAGA binding activity, following exposure of the cells to VP, preceding Pol II recruitment by the VlbR promoter. In the case of the serine protease inhibitor 1 and the AT1R, GAGA binding activity is stimulated by growth factors, and the GAGA box appears to mediate growth factor-mediated gene transcription (Simar-Blanchet et al. 1998, Wyse et al. 2000). VP has recognized effects as a growth factor and activation of the VlaR can transactivate the EGFR in a number of tissues, including kidney mesangial cells and intestinal epithelial cells (Ghosh et al. 2001, Chiu 2002).

In summary, the present demonstration that VP induces recruitment of RNA polymerase II by the V1bR promoter and the levels of V1bR mRNA, supports the view that VP exerts a positive regulatory effect on V1bR expression. As shown in Fig. 8, this effect of VP involves activation of the binding of nuclear proteins to GAGA repeats in the VlbR promoter. This effect is not mediated by protein kinase $\mathrm{C}$ but by transactivation of the EGFR and MAP kinase. The data provide a mechanism by which increased parvocellular VP expression can activate V1bR transcription and contribute to the pituitary V1bR upregulation observed during stress.

\section{Acknowledgements}

The authors are grateful to Dr Joachim Spiess, Max Plank Institute, Goettingen, Germany, for the hypothalamic cell line H32; Dr Maurice Manning, Medical College of Ohio, Toledo, OH, USA for providing the VlbR agonist d[Cha $\left.{ }^{4}\right] \mathrm{AVP}$, and to Dr Claudine Serradeil-Le Gal, Sanofi Synthelabo Recherche, Toulouse, France, for the non-peptide Vla and V1b receptor subtype selective antagonists, SSR 149415 and SR49059 respectively. The authors declare that there is no conflict of interest that would prejudice the impartiality of this scientific work.

\section{References}

Aguilera G 1994 Regulation of pituitary ACTH secretion during chronic stress. Frontiers in Neuroendocrinology 15 321-350.

Aguilera G \& Rabadan-Diehl C 2000 Vasopressinergic regulation of the hypothalamic-pituitary-adrenal axis: implications for stress adaptation. Regulatory Peptides 96 23-29.
Aguilera G, Pham Q \& Rabadan-Diehl C 1994 Regulation of pituitary vasopressin receptors during chronic stress: relationship to corticotroph responsiveness. Fournal of Neuroendocrinology 6 299-304.

Antoni FA 1993 Vasopressinergic control of pituitary adrenocorticotropin secretion comes of age. Frontiers in Neuroendocrinology 14 76-122.

Berkenbosch F, de Goeij DC \& Tilders FJ 1989 Hypoglycemia enhances turnover of corticotropin-releasing factor and of vasopressin in the zona externa of the rat median eminence. Endocrinology 125 28-34.

Biggin MD \& Tjian R 1988 Transcription factors that activate the Ultrabithorax promoter in developmentally staged extracts. Cell 53 699-711.

Bilezikjian LM, Woodgett JR, Hunter T \& Vale WW 1987 Phorbol ester-induced down-regulation of protein kinase $\mathrm{C}$ abolishes vasopressin-mediated responses in rat anterior pituitary cells. Molecular Endocrinology 1 555-560.

Carvallo P \& Aguilera G 1989 Protein kinase C mediates the effect of vasopressin in pituitary corticotrophs. Molecular Endocrinology 3 1935-1943.

Chiu T 2002 Vasopressin-mediated mitogenic signaling in intestinal epithelial cells. American Fournal of Physiology Cell Physiology 282 C434-C450.

Derick S, Cheng LL, Voirol MJ, Stoev S, Giacomini M, Wo NC, Szeto HH, Ben Mimoun M, Andres M, Gaillard RC, Guillon G \& Manning M 2002 [1-deamino-4-cyclohexylalanine] Arginine vasopressin: a potent and specific agonist for vasopressin $\mathrm{V} 1 \mathrm{~b}$ receptors. Endocrinology 143 4655-4664.

Engler D, Pham T, Fullerton MJ, Ooi G, Funder JW \& Clarke IJ 1989 Studies of the secretion of corticotropin-releasing factor and arginine vasopressin into the hypophysial-portal circulation of the conscious sheep. I. Effect of an audiovisual stimulus and insulin-induced hypoglycemia. Neuroendocrinology 49 367-381.

Farkas G, Gausz J, Galloni M, Reuter G, Gyurkovics H \& Karch F $1994 a$ The Trithorax-like gene encodes the Drosophila GAGA factor. Nature 371 806-808.

Ferguson SS 2003 Receptor tyrosine kinase transactivation: finetuning synaptic transmission. Trends in Neuroscience 26 119-122.

de Goeij DC, Kvetnansky R, Whitnall MH, Jezova D, Berkenbosch F \& Tilders FJ 1991 Repeated stress-induced activation of corticotropin-releasing factor neurons enhances vasopressin stores and colocalization with corticotropin-releasing factor in the median eminence of rats. Neuroendocrinology 53 150-159.

Ghosh PM, Mikhailova M, Bedolla R \& Kreisberg JI 2001 Arginine vasopressin stimulates mesangial cell proliferation by activating the epidermal growth factor receptor. American Fournal of Physiology Renal Physiology 280 F972-F979.

Gillies GE, Linton EA \& Lowry PJ 1982 Corticotropin releasing activity of the new CRF is potentiated several times by vasopressin. Nature 299 355-357.

Gilmour DS, Thomas GH \& Elgin SC 1989 Drosophila nuclear proteins bind to regions of alternating $\mathrm{C}$ and $\mathrm{T}$ residues in gene promoters. Science 245 1487-1490.

Jard S, Barberis C, Audigier S \& Tribollet E 1987 Neurohypophyseal hormone receptor systems in brain and periphery. Progress in Brain Research 72 173-187.

Kornberg RD 1999 Eukaryotic transcriptional control. Trends in Cell Biology 9 M46-M49.

Leserer M, Gschwind A \& Ullrich A 2000 Epidermal growth factor receptor signal transactivation. IUBMB Life 49 405-409.

Leverrier S 2000 Purification and cloning of type A/B hnRNP proteins involved in transcriptional activation from the Rat spi 2 gene GAGA box. Biological Chemistry 381 1031-1040.

Li J, Liang VC, Sedgwick T, Wong J \& Shi YB 1998 Unique organization and involvement of GAGA factors in transcriptional regulation of the Xenopus stromelysin-3 gene. Nucleic Acids Research 26 3018-3025. 
Luttrell LM 2003 'Location, location, location': activation and targeting of MAP kinases by $\mathrm{G}$ protein-coupled receptors. Fournal of Molecular Endocrinology 30 117-126.

Plotsky PM 1988 Hypophysiotropic regulation of stress-induced ACTH secretion. Advances in Experimental Medical Biology 245 65-81.

Rabadan-Diehl C, Lolait SJ \& Aguilera G 1995 Regulation of pituitary vasopressin $\mathrm{V} l \mathrm{~b}$ receptor $\mathrm{mRNA}$ during stress in the rat. Fournal of Neuroendocrinology 7 903-910.

Robert J 2005 A novel C-terminal motif is necessary for the export of the vasopressin $\mathrm{V} 1 \mathrm{~b} / \mathrm{V} 3$ receptor to the plasma membrane. Fournal of Biological Chemistry 280 2300-2308.

Simar-Blanchet AE, Legraverend C, Thissen JP \& Le Cam A 1998 Transcription of the rat serine protease inhibitor $2 \cdot 1$ gene in vivo: correlation with GAGA box promoter occupancy and mechanism of cytokine-mediated down-regulation. Molecular Endocrinology $12391-404$.

Soeller WC, Oh CE \& Kornberg TB 1993 Isolation of cDNAs encoding the Drosophila GAGA transcription factor. Molecular and Cellular Biology 13 7961-7970.

Tannahill LA, Sheward WJ, Robinson IC \& Fink G 1991 Corticotrophin-releasing factor-41, vasopressin and oxytocin release into hypophysial portal blood in the rat: effects of electrical stimulation of the hypothalamus, amygdala and hippocampus. fournal of Endocrinology 129 99-107.

Terrillon SSD 2003 Oxytocin and vasopressin V1a and V2 receptors form constitutive homo- and heterodimers during biosynthesis. Molecular Endocrinology 17 677-691.
Volpi S, Rabadan-Diehl C, Cawley N \& Aguilera G 2002 Transcriptional regulation of the pituitary vasopressin $\mathrm{Vlb}$ receptor involves a GAGA-binding protein. Fournal of Biological Chemistry 277 27829-27838.

Volpi S, Rabadan-Diehl C \& Aguilera G 2004 Regulation of vasopressin V1b receptors and stress adaptation. Annals of the New Tork Academy of Sciences 1018 293-301.

Werry TD, Sexton PM \& Christopoulos A 2005 'Ins and outs' of seven-transmembrane receptor signalling to ERK. Trends in Endocrinology Metabolism 16 26-33.

Whitnall MH 1993 Regulation of the hypothalamic corticotropinreleasing hormone neurosecretory system. Progress in Neurobiology 40 573-629.

Wyse BD, Linas SL \& Thekkumkara TJ 2000 Functional role of a novel cis-acting element (GAGA box) in human type-1 angiotensin II receptor gene transcription. Fournal of Molecular Endocrinology 25 97-108.

Young SF \& Aguilera G 2005 Dimerization between vasopressin $\mathrm{V} 1 \mathrm{~b}$ receptor and corticotropin releasing hormone receptor. Endocrine Society 87th Annual Meeting 2005, San Diego, CA, USA. Abstract P-119.

Received in final form 11 January 2006

Accepted 10 March 2006

Made available online as an Accepted Preprint 15 March 2006 